\title{
Gender divisions of paid and unpaid work in contemporary UK couples
}

Anne McMunn, Department of Epidemiology \& Public Health, UCL

Lauren Bird, School of Public Health, Imperial College

Elizabeth Webb, Department of Epidemiology \& Public Health, UCL

Amanda Sacker, Department of Epidemiology \& Public Health, UCL

\section{ABSTRACT}

This article uses data from the UK Household Longitudinal Study to describe how contemporary British couples divide a range of work types. Our findings support the hypothesis, suggested by previous authors, that a shared egalitarian ideology is required for gender equality in divisions of work. In response to bargaining theories, the article also hypothesises that differentials in educational attainment within couples are more strongly associated with gender divisions of work when couple's gender ideology is in conflict. Interaction analysis does not support this hypothesis.

Keywords: gender divisions of work, gender ideology

Corresponding author: Anne McMunn, UCL Research Department of Epidemiology \& Public Health, 1-19 Torrington Place, London WC1E 7HB, a.mcmunn@ucl.ac.uk 


\section{Introduction}

Despite several decades of progress towards gender equality in the workplace, studies continue to consistently show women performing the majority of unpaid domestic work in every country studied (Craig and Mullan, 2011), and the transition to parenthood acts as a trigger for a reversion towards a more traditional 'separate spheres' division of work (Argyrous et al., 2017). There is evidence to suggest that this 'reset' in gender relations carries on throughout adulthood (Kuhhirt, 2012), and permeates material as well as time resources, including gender inequality in earnings and promotion over the life course (SigleRushton and Waldfogel, 2007). A large body of evidence has sought to explain persistent gender inequality in divisions of work at both the macro-level, drawing on cross-national comparison (for example, Fuwa, 2004; Knudsen and Waerness, 2008), and at the individuallevel within couples (Baxter and Hewitt, 2013; Cunningham, 2005, 2007). Sullivan and colleagues (2018) present a theoretical framework for explaining the lagged change in gender divisions of work which combines these two perspectives by linking gender socialisation in early life with couple-level interactions in adulthood within a wider context of ideological norms, social policy environments and material constraints. This framework suggests a vital role at the micro-level for negotiations and decision-making regarding the dividing of work within couples. Micro-level explanations for persistent gender inequality in the division of work within couples have centred around three theoretical models: time availability (Bianchi et al., 2006; Raley et al., 2012), economic models focused on relative and absolute material resources within couples (Kuhhirt, 2012), and socialisation models focusing on the role of gender norms and ideology (Evertsson, 2014). While there is evidence to suggest that gender ideology plays a major role (Cunningham, 2005; Evertsson, 2014), results differ depending on national context and measures considered and have yet to suggest a definitive explanation (Lachance-Grzela and Bouchard, 2010). In this article we argue that extending these micro- 
perspectives from an individual to a couple-level analysis, and considering the role of couples' shared gender ideology and educational background, will provide further understanding of gender divisions of work.

This article makes use of the household structure of the UK Household Longitudinal Study (UKHLS) to investigate how contemporary working-age British couples divide a range of work types. The study adds to previous research by examining associations between shared gender ideology and educational background - homogamy in attitudes and educational attainment, and the role of his and her ideology - and couples' division of work. The study also asks whether differences in educational attainment are more strongly associated with gender divisions of work when couples' gender ideology is in conflict. In what follows we review current evidence on micro-level explanations for persistent gender divisions of work within couples, highlighting the benefits of taking a couple-level approach to investigating homogamy and the role of gender ideology in couples' division of total labour.

\section{Background}

\section{Theories explaining persistent gender divisions of work}

\section{Economic bargaining theories}

Several theories for explaining persistent gender inequality in domestic work have been posited and tested empirically. One explanation comes from an economic perspective emphasising differences in bargaining power as a result of differential access to resources, often operationalized as relative differences in income (Aassve et al., 2014). According to this perspective, the partner with greater power is able to negotiate less participation in domestic work (the underlying assumption being that housework is unpleasant and people want to avoid it). Longitudinal evidence for economic bargaining models is mixed. Share of income has been associated with housework hours in both Australia and Sweden, although 
men did less housework than women regardless of relative resources in both countries (Baxter and Hewitt, 2013; Evertsson and Nermos, 2007). Two recent German studies found relative earnings had little effect on divisions of domestic work within couples (Kuhhirt, 2012; Nitsche and Grunow, 2016). In the UK, there are conflicting results. While Kan (2008) finds that housework hours significantly decrease with increases in relative income, using the same data set, Schober (2013) finds that absolute, rather than relative, income influences shifts towards more traditional divisions of work upon entry into parenthood. Other studies suggest that absolute income is more important than relative income for predicting the number of hours that women spend doing housework as higher levels of income enable couples to purchase external work (Gupta, 2006).

\section{Gender ideology theories}

Economic bargaining theories stress the role of rationality in couples' decision-making. However, this approach does not explain that fact that men continue to do less domestic work than women even in couples where women have more resources (Kuhhirt, 2012) and pays inadequate attention to the role of social norms in influencing intra-household gender dynamics (Agarwal, 1997). So we must turn to alternative explanations such as socialisation theories emphasising the influence of gender ideology. As described by Sullivan and colleagues (2018), gender norms influence all levels of society, from macro-level government policies and distribution of resources, to the micro-level of individual attitudes and behaviours. This study follows Davis and Greenstein (2009) and Evertsson (2014) in using the term 'gender ideology' to encapsulate the continuum in individual-level attitudes regarding the notion of 'separate spheres' in gender divisions of laour within couples. Gender ideology is fairly consistently associated with gender divisions in work in expected directions: women with more egalitarian attitudes do less domestic work and more paid work than traditional women while men with more egalitarian attitudes do more domestic work 
than more traditional men (Aassve et al., 2014; Cunningham, 2005), although such associations are not always interpreted as causal.

Yet, even in the presence of egalitarian ideology, gender divisions of work persist as do paradoxical feelings of fairness amongst both men and women regarding this persistent unequal distribution (Carriero, 2011). In their review of explanations for persistent gender inequality in housework, Lachance-Grzela and Bouchard (2010) conclude that "no perspective yet offers a clear explanation of why women still do the bulk of housework even when they display the personal characteristics that favor a more egalitarian division of household labour." (p. 774). We suggest that this may partly be because broader social norms support the maintenance of traditional gender identities and divisions of work (to a greater or lesser extent depending on the cultural context), and while gender ideology is becoming more egalitarian over time, change is happening more quickly for women than for men, on average (Taylor and Scott, 2018) which suggests a certain level of potential disagreement within couples. As Evertsson (2014) notes, the strength of gender norms is such that a shared egalitarian ideology may be required for couples to achieve greater gender equality in divisions of work. Thus, this article proposes that investigating gender ideology jointly within couples may have more explanatory power in its associations with gender divisions of work, and that the concept of 'homogamy', mainly used in the study of educational similarity within couples (Blossfeld and Timm, 2003), may also be useful in the study of gender ideology within couples.

Studies are limited in the extent to which they consider both partners' gender ideology and those that do consider them separately rather than jointly. Studies in Sweden (Evertsson, 2014) and the UK (Schober, 2013) have shown that his and her ideology significantly influences their own number of housework hours. In Sweden women's behaviour is also influenced by their partner's ideology: those with egalitarian partners spend less time on 
housework than those with less egalitarian partners, but women's gender ideology is not associated with the amount of time their male partners spend on housework (Evertsson, 2014). Evidence from Britain suggests that women's gender ideology only influences their own housework and paid work hours, not those of their partner, and there is no association for men between gender ideology (theirs or their partner's) and hours spent in housework or paid work (Schober, 2013). A study in Germany found that the ideology of each partner equally and significantly predicted divisions in housework (Nitsche and Grunow, 2016). No study has yet to look at the agreement or homogamy of gender ideology between couples.

\section{Time availability and gender divisions of total labour}

The time availability hypothesis is a third explanation for persistent gender inequality in the performance of domestic work and says that individuals who spend more time on paid work have less time to spend on domestic work (Bianchi et al., 2006; Raley et al., 2012). Time availability models point to evidence that both women and men who are employed perform less housework than those who are not (Bianchi et al, 2006). However, rather than being an explanatory theory for gender divisions of work, time availability models are, in fact, a description of the very phenomenon they seek to explain - gender divisions of work. Men and women's allocation of time to one form of work form over another is, at heart, the definition of gender divisions of work. Time availability models assume that employment hours influence availability for domestic work equally for men and women. However, evidence suggests that this is not the case. Using Australian time use data, Craig and Powell (2011) showed that mothers spent more time on domestic work when their partners worked non-standard hours, but the inverse was not true; mother's work schedules did not influence their partner's time use allocation. Other evidence regarding the influence of women's work hours on men's time use is more mixed (Cunningham, 2007; Raley et al., 2012). Results fairly consistently showing that women do more childcare and housework than men 
regardless of levels of paid employment (Chelsey and Flood, 2017), with working mother likely to forego personal time to ensure they continue to provide quality parental care (Bianchi et al., 2006).

Couples are likely to consider all work responsibilities in their decision-making about how work is divided between them within wider processes of gender relations, such as gendered norms and ideology, but also gender inequality in pay and gendered expectations in the workplace. For this reason, rather than considering participation in one type of work as explaining participation in another, we consider all gendered work types in combination. In doing so we follow Glucksmann's (1995) “Total Social Organisation of Labour” (TSOL) which she developed as a descriptive framework for broadening the conceptualization of labour - and the scope of labour research - to move beyond paid market employment. Both Crompton (2006) and Gornick and Meyers (2003) have usefully drawn on the TSOL in developing frameworks for thinking about gender divisions of labour at the macro-level. To our knowledge this is the first study which seeks to operationalize the TSOL empirically at the couple level.

\section{Hypotheses}

This article builds on current evidence by investigating the ways that couples in the UK divide and/or share multiple types of work simultaneously, and then by examining potential couple-level explanations for these gender divisions, more specifically couples' homogamy in their gender ideology and educational attainment. By considering multiple work types simultaneously within couples, we potentially identify non-normative and less common ways of dividing work which are unlikely to be uncovered by looking at the number of hours spent in work types separately at the individual level. Within the couple, we ask whether a shared egalitarian ideology is required for gender equality in work divisions, as suggested by Evertsson (2014), and what happens when couples disagree in their ideology. UK trend data 
on men and women's attitudes suggest fairly dramatic shifts towards more egalitarian ideologies (Phillips et al, 2018); however, there is like be a relatively high proportion of couples in which the man has more traditional attitudes than his female partner (Taylor and Scott, 2018). This may partly explain the lack of behavioural change in this area with evidence from Sweden suggesting that men's gender ideology was more influential on their partner's housework hours than women's (Evertsson, 2014). Thus, we investigate whether men's ideology is more strongly associated with the gender divisions of work within couples where there is disagreement. Finally, where couple's couples disagree in their gender ideology, perceptions of status may influence bargaining processes regarding divisions of work types (Kan, 2008). One potential source of status distinction is educational attainment (Datta Gupta \& Stratton, 2010). Thus, we also ask whether differentials in educational attainment within couples is particularly important when couples disagree in their gender ideology. Based on previous theoretical and empirical literature, we hypothesise the following:

1. Persistent gender norms and an ambivalent policy environment mean that, while more sharing across work forms will occur amongst younger couples, domestic work will fall primarily to women across division-of-work groups.

2. The strength of gendered social norms means that a shared egalitarian ideology is required for a more equal division of work.

3. Because the UK is still emerging from a traditional status quo in which change in behaviour in the domestic sphere is largely required by men, men's gender ideology will be more strongly associated with couples' division of work than women's gender ideology. 
4. Educational differences within couples will be more strongly associated with gender divisions of work in expected directions (more education linked with greater participation in paid market work and less in unpaid domestic work) when couples are conflicting in their ideology.

The main contribution of this study is to focus theoretical and empirical attention at the level of the couple, first in providing a detailed picture of how contemporary UK couples are currently dividing their total work responsibilities, and, then by examining associations with shared gender ideology, and educational homogamy. Yet we recognize the importance of macro-level social context in influencing couple's decision-making regarding work forms (Fuwa, 2004). A key characteristic of the UK context has been the dominance of the 'modified male-breadwinner' model, in which fathers are employed full-time and mothers part-time, as a way of combining employment and parenting in the context of relatively little provision for childcare and parental leave, and a culture of long work hours amongst full-time employees (Crompton, 2006). Maternity leave provision has improved in the UK over the past twenty years with statutory maternity leave extended to 12 months in 2006, although many of the couples in our study would have had their children prior to this time. Since 2003, UK fathers have access to two weeks of statutory paternity leave, but as of April 2015, mothers can opt to give some of their leave provision to their partners; however, uptake of this option remains very low. In terms of childcare, tax-free vouchers for 15 hours of childcare per week became available to parents of children aged $3+$ in 2005 , but the sector remains under-funded which limits the number of places available to parents. In relation to adult social care, the UK relies largely on informal family provision (Carers Trust, 2018).

\section{Methods}

\section{Data}


This study and takes advantage of the household structure of the large, national UK Household Longitudinal Study (UKHLS). UKHLS is a large panel survey of around 40,000 households who have been surveyed annually since 2009/10. Because our focus in on gender, we restrict our sample to co-resident, opposite sex couples of working age. We include couples across working ages, rather than those in the early years of childrearing, as gendered divisions of work have been shown to persist well beyond transitions to parenthood (Loretto and Vickerstaff, 2015). All household members aged 16+ are invited to participate and opposite sex, co-resident couples at wave 2 in which both partners were aged 16-65 years were included. Wave 2 was selected as it was the first wave to collect information on the number of hours spent doing housework and caregiving. The analytic sample for this study included 8,513 couples who had complete information on all of our variables of interest. This is $70 \%$ of the 12,156 working age opposite-sex couples with information on all work variables. The two samples did not differ significantly on any of the analysis variables (analysis available upon request). Most of the reduction in sample was due to missing data on measures of gender attitudes.

\section{Measures}

\section{Gender divisions of work}

We include four types of work to create a typology of gender divisions of 'total labour' within couples. We have selected work types that are generally of interest in this area due to their gendered nature: housework, paid employment and childcare. We extend this to include adult care in recognition that gender divisions of work persist beyond the childrearing years and adult caregiving remains gendered (Author A, Author B). Seven work variables were used in the latent class analysis: weekly hours spent in paid work (two variables: one for his hours, one for her hours), weekly hours providing care for an adult (two variables: his and 
hers), and weekly hours spent doing housework (two variables: his and hers), and one variable for the mother's report of who has main responsibility for childcare if there are children in the household (mother, partner, shared or other). The latter was reported by both partners, but to avoid collinearity, only mothers' reports were used. Details of the latent class analysis are provided in the 'Analytic Techniques' section below.

\section{Gender ideology within couples}

Initially, separate gender ideology scales were derived for each member of the couple by combining responses to the following five items asking about attitudes towards gender divisions of work (see Annex). Responses were scored from 0-4, from strongly agree to strongly disagree (items 3 and 5 were reverse coded) and the five items were summed to give a scale score ranging 0-20 with higher scores indicating more egalitarian and lower scores indicating more traditional attitudes. As shown in Annex Table 2, women were a little more egalitarian than men, on average (mean $=12.7$ for women and 12.1 for men). The Spearman's correlation coefficient for his and her gender ideology scores was 0.43 . In order to investigate couple homogamy in gender ideology, we categorized the gender ideology scores into tertiles and based on his and her tertiles we derived the following five category couple-level gender ideology variable: If both were in the most egalitarian tertile they were 'Both egalitarian', if both in the most traditional tertile, 'Both traditional' and if both in the middle tertile, 'Both middling'. Couples in which women were in a more egalitarian tertile than their partners appear in the 'Woman more egalitarian' group, and couples in which men were more egalitarian than their partners appear in the 'Man more egalitarian'.

\section{Educational differentials within couples}


Because earnings are intrinsically linked to past and current labour market participation, the use of relative earnings to measure potential power differentials is problematic for this study which focuses on describing interwoven work types, including paid work. Studies have shown relative education to relate to divisions of housework in a similar way to relative income measures (Datta Gupta and Stratton, 2010); thus, we use differences in educational attainment, although we recognize that educational differences are not a direct measure of decisional power within couples. Six categories of highest educational attainment were used: 1. 'no qualifications', 2.' 'other qualifications' 3. 'GCSEs or equivalent' (lower secondary education to age 16) 4. 'A levels or equivalent' (higher secondary education to age 18) 5.'degree' or 6. 'higher degree.' Couples were then grouped into three categories: those in which men and women had equal educational attainment (35\%), those in which men had higher attainment than their partners (31\%), and those in which women had higher educational attainment than their partners (34\%). Amongst those who had equal attainment, it was common for both members of the couple to have A-level or GCSE qualifications, making up about a third of this group. In couples with unequal attainment than their partners, the largest groups, had A-level qualifications combined with a partner who attained GCSE qualifications. The remainder of this group was spread fairly evenly across attainment combinations although very few people with degrees or higher degrees with partners who had no educational qualifications. These patterns were equally true regardless of whether it was men or women who had higher qualifications than their partners.

\section{Covariates}

Each covariate was selected on the basis of both empirical evidence and conceptual plausibility of associations with divisions of work, as well as gender ideology. Age of both members of the couple with the average age of the couple was used in multivaritate 
regression models. Equivalised household income was derived using the household's net income and an OECD equivalization variable; equivalised household income is continuous and in thousands of pounds. Women's income as a share of household income is also shown in descriptive results. Marriage is a highly gendered institution and has been shown to be associated with gender ideology (Fan and Marini, 2000). Therefore, we control for whether couples are formally married or not as well as the number of pre-school aged children (ages 0-4) and number of school aged children (5-15) in the household.

\section{Analytic Techniques}

This article builds on previous work considering multiple work types separately (Kuhhirt, 2012; Schober, 2013), by characterising how couples divide multiple work types simultaneously. Four work types previously shown to be gendered are included: paid market work, unpaid domestic housework, unpaid domestic childcare and unpaid informal provision of care to an adult. To do this, we adopt a latent class approach. Latent class analysis (LCA) is a statistical method which can be used to cluster individuals into groups based on their similarity on observed characteristics that are thought to represent an underlying theoretical concept, in this case, divisions of total labour. Here LCA is used to categorise couples based on the amount of work that each member does in relation to four work types. The approach taken to select the number of division-of-work groups was largely empirical, although this empirical approach was conceptually informed as we will explain. A two-group model was first fitted and then the number of groups increased, assessing the fit of each using Akaike's Information Criterion (AIC), Bayesian Information Criterion (BIC), and the model's best log likelihood. Moving through solutions with a greater number of groups, model fit was still 
improving at the eleven group solution according to the AIC, BIC and log likelihood criteria. ${ }^{1}$ However, the models with 9 and more groups produced some very small groups (less than $1 \%$ of the sample) that were indistinct conceptually from other small groups. We say our empirical approach was conceptually informed because, while changes to the BIC slowed after the seven class solution, we chose eight groups as the additional class provided an important conceptual distinction, drawing a group of dual-earner couples who were providing care to an adult. The resulting eight gender-division-of-work groups are described in the results section. A table showing the distribution of the seven work variables within each LCA division-of-work group appears in the Annex Table 1.

To investigate the extent to which indicators of couples' homogamy in gender ideology and educational attainment were associated with divisions of work, multinomial logistic regression was conducted with the work groups as the outcome variable. These models included each of the covariates, couples' joint gender ideology, and couples' educational homogamy. Models were then rerun with the addition of an interaction term between couples' gender ideology and educational homogamy (not shown in the Table). Once the eight-group solution was accepted, the LCA, multinomial regressions and interaction analysis were all run together using Mplus 7.

\section{Results}

\section{Gender divisions of work in contemporary couples in the UK}

The Figure shows the percentage of couples in each of the eight division-of-work groups derived by the LCA, and the groups are shaded from darkest to lightest to denote a grading of

\footnotetext{
${ }^{1}$ We sought changes in the BIC or AIC between $\mathrm{N}$ and $\mathrm{N}+1$ classes of $<10$ (Burnham et al., 2011); however, the minimum difference in either BIC or AIC across our models was $>600$. So we adopted a pragmatic criterion of no class smaller than $\mathrm{N}=100$, or $1 \%$ in conjunction with consideration of the conceptual distinction between the groups produced.
} 
most to least egalitarian in their divisions of work. The Annex Table 2 shows the demographic, social and economic characteristics of each of the groups.

Half of the groups could be considered to display a relatively egalitarian division of work. Two small groups may be considered the most egalitarian: $6 \%$ of couples in a femaleearner group ('Female-earner/shared-domestic' in Figure and Tables), and 1\% in a group in which men spent long hours doing housework ('Male long hours domestic'). The femaleearner was the only group in which men's contribution to the housework was similar to their partner's, and this group had the highest proportion of women with educational qualifications higher than their partners. While men tended to be older than women across the study on average, this age gap was considerably wider amongst female-earner couples, suggesting these non-employed male partners may have taken early retirement. Female-earner couples were less likely than many other groups to have dependent children at home.

The 'Male long hours domestic' group was marked by male non-employment and housework - all men in this group spent more than twenty hours per week on housework and, while most women did housework too, 30\% did not (which was much higher than other groups). This group had relatively high levels of adult caregiving responsibilities, and men did more than women with over $40 \%$ of men in these couples providing 20 or more hours of adult caregiving per week. Given the relatively high levels of adult care for men in these couples, we checked whether they were caring for their female partner, but this was not generally the case. These two groups had the highest levels of men having main responsibility for childcare, at about a quarter of those who had children under age 16 at home (although only $30 \%$ of female-earner couples had children under age 16 at home).

The other two relatively egalitarian groups were two groups of dual-earner couples. In the largest group of all, at $41 \%$ of all couples, both members of the couple were in full-time employment and had little or no caregiving responsibilities ('Dual-earner/low-care'). Men in 
these couples performed more housework than in some of the other groups, although women still did more of the housework than their partners, as was the case with nearly all of the groups. Eight percent of couples were in the other dual-earner group ('Dual-earners/dualcaregiver') which was distinguished by adult caregiving responsibility: all women in this group spent at least some time during the week providing care to an adult and half of all men did as well. Despite all women in this group combining employment with caregiving for an adult, they still performed more housework than men. A majority of couples in this group did not have dependent children at home. The two dual-earner groups had the highest incomes.

Two percent of couples were in a group ('Male-earner long hours/female-earner + domestic') in which women were employed, about half part-time, but men worked long hours: every man in this group worked 60 hours per week or longer. Perhaps for this reason, women in these couples combined paid employment with relatively high levels of childcare responsibility and spent more time on housework than women in many other couples.

Two groups were characterized by a highly traditional division of work. In the largest of these, and the second largest group over all at $28 \%$, men were predominately employed full-time, while over half of women were not in paid work, and the remaining were employed part-time ('Male-earner/female-domestic'). Women in these couples performed large amounts of housework, with over half spending more than twenty hours per week on housework, and $63 \%$ of men contributed fewer than 5 hours housework per week. Seventy percent of these couples had children under 16 in the home, and women had responsibility for childcare in the large majority of cases. The smallest group to emerge (at $1 \%$ ) was a highly traditional group of couples ('Male-earner/female long hours domestic') in which all of the women performed 20 hours or more of housework per week and $60 \%$ of men reported doing less than five hours of housework per week. Over two-thirds of women in these most traditional couples were not in paid work with nearly a quarter employed part-time. The 
majority (four-fifths) had children aged under 16 years at home, with the majority reporting childcare as being mostly the woman's responsibility.

The third most common group (at 13\%) was somewhat older, generally in their fifties and early sixties, and were characterized by low work attachment for both members of the couple, and little to no caregiving responsibilities as they generally did not have school-age or pre-school children at home ('Non-employed/low-care'). Women in these couples did relatively high levels of housework, suggesting that these couples may have previously followed a traditional gender division of work. This, combined with the age profile and lack of dependent children at home suggests that this group of couples had children previously and are in the 'empty nester' life stage; indeed, they may have grandparental care responsibilities outside the home. They had the lowest median income of all groups.

FIGURE 1 ABOUT HERE

\section{Homogamy in gender ideology and couples' divisions of work}

In unadjusted bi-variate results (Annex Table 2), both groups of traditional male-earner couples were much more likely to hold a homogamous traditional gender ideology (at 21\%$23 \%$ each compared with $14 \%$ amongst couples overall) and least likely to hold a homogamous egalitarian gender ideology, particularly for the small group of extremely traditional 'Male-earner, female long hours domestic' couples, amongst whom only $2 \%$ held homogamous egalitarian ideologies compared with $21 \%$ in couples overall. Similarly, both groups of dual-earner couples and the female-earner couples were more likely to hold a homogamous egalitarian gender ideology (27-30\% for dual-earner couples and $24 \%$ for female-earner couples). 
Table 1 shows odds ratios for the multinomial regression models. The odds ratios compare each of the division-of-work groups with the most common group, the 'Dualearner/low care' group. Odds ratios greater than one suggest that couples in that group are more likely than the reference group to have the characteristic in question and an odds ratio lower than one suggests that they are less likely. So, the Table shows that, after adjusting for all covariates including educational differentials within couples, couples that don't share an egalitarian gender ideology are significantly more likely to be in one of the two male-earner groups, the 'Male-earner long hours/female-earner + domestic' group in which men worked long hours and women combined employment with domestic work, or in the 'Nonemployed/low care' group than in the 'Dual-earner/low care' group, suggesting that a shared egalitarian ideology is required for less traditional divisions of work. Couples who share a traditional gender ideology are extremely likely to be in one of the two male-earner groups, particularly in the most traditional 'Male-earner/female long hours domestic' group.

Differences between the non-homogamous groups were small, suggesting that men's gender ideology was not more strongly associated with couple's division of work than women's gender ideology. There were no significant differences in gender ideology between the four groups with more egalitarian divisions of work - the two dual-earner groups, the female-earner and the male domestic work groups.

\section{TABLE 1 ABOUT HERE}

\section{Homogamy in educational attainment and couples' divisions of work}

Even after controlling for gender ideology, differences in educational attainment were associated with some division-of-work groups. Men had higher educational qualifications 
than their partners in the 'Male-earner/female domestic' group and lower educational qualifications than their female partners in 'Female-earner/shared domestic' couples. Women were less likely to have higher qualifications than their partners in the 'Non-employed/low care' group. We hypothesized that educational differentials may be more important in couples whose gender ideologies were in conflict. Interaction analysis of couples' shared gender ideology and differences in their educational attainment (not shown) did not show differences according to education differentials in the non-homogamous gender ideology couples. Rather, interaction analysis showed that, couples were significantly more likely to be in the most traditional division of work group (the 'Male-earner/female long hours domestic' group) when men had higher educational qualifications than their partners and the couples shared a homogamous traditional ideology.

\section{Discussion}

Using a large, nationally representative study of UK couples, this article has asked whether a shared egalitarian ideology is associated with more egalitarian sharing of four gendered work types, and, where gender ideology is in conflict, whether men's ideology was more strongly associated with divisions of work than women' ideology. Finally, the study explores whether educational differences are more strongly associated with gender divisions of work when couples' gender ideology is in conflict. Results supported only the first of these hypotheses. This article has also provided a novel description of divisions of work within contemporary British couples across four work types simultaneously, revealing some unfamiliar groups and providing richer understanding of different ways that well-known couple types divide multiple work forms.

By conducting couple-level analysis of homogamy in gender ideology, this study suggests that a shared egalitarian ideology is required for a more equal division of work, and 
one egalitarian ideology within a couple is not sufficient in the face of slow-to-change gender norms. This builds on previous work showing that gender divisions of work persist in the face of individual egalitarian ideology (Evertsson, 2014). Based on previous results showing men to be more likely than women to hold traditional views on gender (Taylor and Scott, 2018), and evidence from Sweden suggesting that men's ideology influenced women's housework hours, but women's ideology did not influence men's (Evertsson, 2014), our second hypothesis was that men's ideology would be more strongly associated with divisions of work than women' ideology. While women were more likely than men to hold egalitarian gender attitudes in our study, our second hypothesis was not supported. Differences between these results and those from the Swedish study are unlikely to reflect differences in national context given stronger egalitarian social norms in Sweden compared with the UK. Most likely, the difference is explained by the focus on couple-level ideological homogamy here; the effect of gender ideology on housework hours may be contingent on partner's ideology in Sweden as it appears to be in the UK. The majority of previous studies have focused on individual level associations, and our results are broadly in line with their fairly consistent finding that egalitarian gender ideology is associated fewer hours spent in domestic work amongst women (Nitsche and Grunow, 2016).

Despite the strength of association we find between shared egalitarian gender ideology and divisions of work, it is important to note that women still did more domestic work than men in our two largest egalitarian groups (both dual-earner groups). It was only in female-earner couples and the very small group of men doing long hours of domestic work that men did as much or more domestic work than women. This suggests that even a shared egalitarian ideology may not be sufficient to counter potential obstacles to equal sharing in the UK. It is also important to highlight the limitation of the cross-sectional design of this study as evidence suggests that gender attitudes shift after transitions to partnership and 
parenthood as men and women adapt their attitudes to the reality of their lived experience (Carlson and Lynch, 2013).

Our findings on differences in educational attainment and gender divisions of work are largely in line with those showing links between relative earnings and divisions of domestic work (Kan, 2008). These associations are likely to reflect a range of processes. Higher educational qualifications may increase bargaining power through status differentials and/or a greater earning potential. Also, higher educational attainment may make employment easier to maintain. Our analysis extended this work to show educational differences between couples to be most strongly linked with their division of work when they share a traditional ideology. In particular, couples' with a shared traditional ideology in which the man had higher educational qualifications than their female partner were the most likely to be in the small group with an extremely traditional division of work whose key distinguishing feature was the long hours of housework women were doing. It is not possible to disentangle the causal processes for these couples in our study design. Descriptive results show that women in this group were amongst the most likely to have no educational qualifications (Annex Table 2). It is possible that this group is comprised of ethnic or religious groups that espouse traditional gender norms. We have not investigated ethnicity or religious affiliation as part of this study, but others have shown ethnic variation in women's employment in this data set (Khoudja \& Platt, 2018).

Our focus on couple-level analysis extends to our method for characterising divisions of work within couples. This has uncovered some less-known, distinct types of division as well as fleshing out more detail and variation in the standard binaries of dual-earner/more egalitarian - male-earner/more traditional. In addition to the small group of extremely traditional couples in which women performed high levels of housework described above, our results uncovered a small group of couples in which men were not employed and did high 
levels of housework and care for adults and children. Our results also identified a group of couples in which women had stronger ties to paid employment than their male partners and in which housework was shared equally. Couples in this group were a little bit older and were much less likely than most other groups to have school-aged children at home, so it may be that non-employment for men in these couples was due to early retirement or unemployment rather than exiting the labour market to care for children or adults. It was only by considering the combination of work types together that our study was able to identify these less common groups of couples combining work forms in novel ways.

Even amongst the more commonly expected division-of-work groups, considering multiple work types together in combination revealed additional complexity. A straightforward 'modified male-breadwinner' model that is generally considered the hallmark format for families combining work and parenting in the UK (Crompton, 2006) did not emerge from our analysis. Rather, when multiple work types were considered together for both members of the couple, women employed part-time were generally combined with non-employed women in the main male-earner groups, or were combined with full-time employed women to form the small group of employed women partnered with men working extremely long hours each week. These, often highly educated, women epitomized a 'second shift', combining paid employment with high levels of housework and childcare, potentially struggling to maintain their investment in employment during childcare years with a partner strongly committed to paid market work. In addition, our inclusion of adult care distinguished a second, smaller dual-earner group in which couples provided relatively high levels of adult care. Thus, we were able to distinguish this sub-group of dual-earners that is qualitatively different from the dominant, largest groups of dual-earner couples without caregiving responsibilities.

Taken together our couple-level 'total work' approach suggests unfamiliar groups of couples who warrant further detailed study. In addition, the inclusion of couples across 
working age meant that life stage provided some of the distinction between division-of-work groups which indicates the importance of following these couples over time. Because intense caregiving responsibilities, both for children and adults, are transitory in nature and occur during a relatively small fraction of the life course, couples with these responsibilities make up a minority in our study. Dual-earner groups, which make up the largest groups of couples, were generally younger and less likely to have children than more traditional groups. For the younger dual-earners in particular it will be important to follow these groups over time through the study to observe whether their divisions of work shift towards a more traditional set up if they become parents as has been observed so often previously (Schober, 2013). Indeed, our third most common group of slightly older couples in their fifties and early sixties, who were often not in paid employment and generally did not have school-age or preschool children at home, were distinguished by their life stage. These possible 'empty nesters', who may have provided care to grandchildren outside the home as this was not picked up by our data, held relatively traditional gender attitudes, and women in these couples generally had lower educational attainment than their partners

\section{Conclusion}

Results from this analysis of divisions of work in contemporary UK couples suggests that gender equality in divisions of work is rare and gender norms remain strong. Individual's own gender ideology is a starting point for shaping behavior but currently it remains difficult to implement an egalitarian ideology without the support of a partner with shared ideology. The importance of a shared egalitarian ideology seen in our study suggests gender norms, perhaps through early education and both traditional and social media, as key targets for encouraging social change. However, even with a shared egalitarian ideology, social structural constraints may restrict the extent to which couple-level negotiated egalitarian 
preferences can be acted upon, and our results do not contradict the large body of evidence showing that entry to parenthood remains a key life transition for gender relations within couples; the largest egalitarian groups in this study were less likely to have children. Studies suggest that fathers who are involved in parenting early-on remain more involved over time (Author C) and growing up in households in which fathers and mothers play an equal role in domestic life is likely to be key to changing gender norms regarding 'separate spheres'. Evidence from Nordic countries suggests that provision of adequately-paid, 'use it or lose it' paternity leave provision and high-quality affordable childcare are pre-requisites for achieving substantial uptake of paternity leave and greater gender equality in employment (Kvande, 2017). Even with these policy supports in place, and in the context of greater gender equality in both norms and behaviour, Nordic women continue to do more housework than Nordic men (Evertsson, 2014). This suggests that such policy levers may not be sufficient for achieving complete equality, but they are a necessary start.

\section{Acknowledgements}

The authors would also like to thank reviewers for their helpful input in improving the article.

\section{Funding}

Work for this paper was supported by the ESRC International Centre for Lifecourse Studies in Society and Health (ICLS) (ES/J019119/1). The UK Household Longitudinal Study is funded by the Economic and Social Research Council and various Government Departments, with scientific leadership by the Institute for Social and Economic Research, University of Essex, and survey delivery by NatCen Social Research and Kantar Public. The research data are distributed by the UK Data Service. 


\section{References}

Aassve A, Fuochi G, and Mencarini L (2014) Desperate Housework: Relative Resources, Time Availability, Economic Dependency, and Gender Ideology Across Europe. Journal of Family Issues 35(8): 1000-1022.

Agarwal B (1997) "Bargaining" and Gender Relations: Within and Beyond the Household. Feminist Economics 3: 1-51.

Argyrous G, Craig L, and Rahman S (2017) The Effect of a First Born Child on Work and Childcare Time Allocation: Pre-post Analysis of Australian Couples. Social Indictors Research 131(2): 831-851.

Baxter J, Hewitt B (2013) Negotiating domestic labor: women's earnings and housework time in Australia. Feminist Economics 19(1): 29-53.

Bianchi S, Robinson J, and Milkie M (2006) Changing rhythms of American family life. New York: Russell Sage Foundation.

Blossfeld H-P, and Timm A (1998) (eds) Who Married Whom? Educational Systems as Marriage Markets in Modern Societies. Dordrecht: Kluwer Academic Publishers.

Burnham K P, Anderson D R, and Huyvaert, K P (2011) AIC model selection and multimodel inference in behavioral ecology: some background, observations, and comparisons. Behavioral Ecology and Sociobiology 65: 23-35.

CarersTrust. Key facts about carers and the people they care for | Carers Trust [Internet]. 2017 [cited 8 Dec 2018]. Available: https://carers.org/key-facts-about-carers-andpeople-they-care

Carlson D L, Lynch J L (2013) Housework: Cause and consequence of gender ideology? Social Science Research 42(6): 1505-1518.

Carriero R (2011) Perceived Fairness and Satisfaction with the Division of Housework Among Dual-Earner Couples in Italy. Marriage \& Family Review 47: 436-458. 
Chesley N, Flood S (2017) Signs of Change? At-Home and Breadwinner Parents' Housework and Child-Care Time. Journal of Marriage \& Family 79: 511-534.

Craig L, Mullan K (2011) How Mothers and Fathers Share Childcare: A Cross-National Time-Use Comparison. American Sociological Review 76(6): 834-861.

Craig L, Powell A (2011) Non-standard work schedules, work-family balance and the gendered division of childcare. Work, Employment and Society 25(2): 274-291.

Crompton R (2006) Employment and the family: the reconfiguration of work and family life in contemporary societies. Cambridge: Cambridge University Press.

Crompton R, Brockmann M, and Lyonette C (2005) Attitudes, women's employment and the domestic division of labour: a cross-national analysis in two waves. Work, Employment and Society 19(2): 213-233.

Cunningham M (2005) Gender in cohabitation and marriage: the influence of gender ideology on housework allocation over the life course. Journal of Family Issues 26(8): 1037-1061.

Cunningham M (2007) Influences of Women's Employment on the Gendered Division of Household Labour Over the Life Course: Evidence From a 31-Year Panel Study. Journal of Family Issues 28(3): 422-444.

Datta Gupta N, Stratton LS (2010) Examining the impact of alternative power measures on individual time use in American and Danish couple households. Review of Economics of the Household 8(3): 325-343.

Davis SN, Greenstein TN (2009) Gender ideology: components, predictors, and consequences. Annual Review of Sociology 35: 87-105.

Evertsson M (2014) Gender Ideology and the Sharing of Housework and Child Care in Sweden. Journal of Family Issues 35(7): 927-949.

Evertsson M, Nermo M (2007) Changing resources and the Division of Housework: A 
Longitudinal Study of Swedish Couples. European Sociological Review 23(4): 455470.

Fan P-L, Marini MM (2000) Influences on gender-role attitudes during the transition to adulthood. Social Science Research 29: 258-283.

Fuwa M (2004) Macro-level gender inequality and the division of household labor in 22 countries. American Sociological Review 69: 751-767.

Gershuny J, Sullivan O (2003) Time use, gender, and public policy regimes. Social Politics 10: 205-227.

Glucksmann M (1995) Why 'Work'? Gender and the 'Total Social Organization of Labour'. Gender, Work and Organization 2(2): 63-75.

Gornick J, Meyers M (2003) Families that Work: Policies for Reconciling Parenthood and Employment. New York: Russell Sage Foundation.

Gupta S (2006) Her money, her time: Women's earnings and their housework hours. Social Science Research 35(4): 975-999.

Kan MY (2008) Does gender trump money? Housework hours of husbands and wives in Britain. Work, Employment \& Society 22(1): 45-66.

Kan MY, Sullivan O, and Gershuny J (2011) Gender Convergence in Domestic Work: Discerning the Effects of Interactional and Institutional Barriers from Large-scale Data. Sociology 45(2): 234-251.

Khoudja Y, Platt L (2018) Labour market entries and exits of women from different origin countries in the UK. Social Science Research 69: 1-18.

Knudsen K, Waerness K (2008) National context and spouses; housework in 34 countries. European Sociological Review 24: 97-113.

Kuhhirt M (2012) Childbirth and the long-term division of labour within couples: how do substitution, bargaining power and norms affect parents' time allocation in West 
Germany? European Sociological Review 28(5): 565-582.

Kvande, Elin. (2017) Access to parental leave - lessons from Norway. Labour market and working parents post Brexit, UCL. Grand Challenge of Justice and Equality, UCL. 5 April 2017.

Lachance-Grzela M, and Bouchard G (2010) Why Do Women Do the Lion's Share of Housework? A Decade of Research. Sex Roles 63:767-780.

Loretto W, and Vickerstaff S (2015) Gender, age and flexible working in later life. Work, Employment and Society 29(2): 233-249.

Nitsche N, and Grunow D (2016) Housework over the course of relationships: Gender ideology, resources, and the division of housework from a growth curve perspective. Advances in Life Course Research 29: 80-94.

O’Brien M, and Twamley K (2017) Fathers Taking Leave Alone in the UK - A Gift Exchange Between Mother and Father?. In: O'Brien M., Wall K. (eds) Comparative Perspectives on Work-Life Balance and Gender Equality. Cham: Springer

Phillips D, Curtice J, Phillips M, and Perry J (eds) (2018) British Social Attitudes: The 35th Report. London: The National Centre for Social Research.

Raley S, Bianchi SM, and Wang W (2012) When do fathers care? Mother's economic contribution and fathers' involvement in child care. American Journal of Sociology 117: $1422-1459$.

Schober PS (2013) The Parenthood Effect on Gender Inequality: Explaining the Change in Paid and Domestic Work When British Couples Become Parents. European Sociological Review 29(1): 74-85.

Sigle-Rushton W, and Waldfogel J (2007) Motherhood and women's earnings in AngloAmerican, Continental European, and Nordic Countries. Feminist Economics 13: 55- 
92.

Sullivan O, Gershuny J, and Robinson JP (2018) Stalled or Uneven Gender Revolution? A Long-Term Processual Framework for Understanding Why Change Is Slow. Journal of Family Theory \& Review 10(1): 263-279.

Treas J, and Lui J (2013) Studying housework across nations. Journal of Family Theory \& Review 5(2): 135-149.

Anne McMunn is Professor of Social Epidemiology and currently Head of the Research Department of Epidemiology \& Public Health at UCL. Her research makes use of the UK's longitudinal population data investments to investigate changes in gender divisions of labour, provision of care to both adults and children, social relationships and social participation in relation to health and wellbeing amongst children, working age adults and older people from a gender perspective. 
Figure 1: Percentage of couples in wave 2 of the UK Household Longitudinal Study in each of the EIGHT COUPLE DIVISION OF WORK TYPES, SHADED DARK TO LIGHT FOR MOST (DARKEST) TO LEAST (LIGHTEST) EGALITARIAN IN GENDER ATTITUDES.

Dual-earners/low care

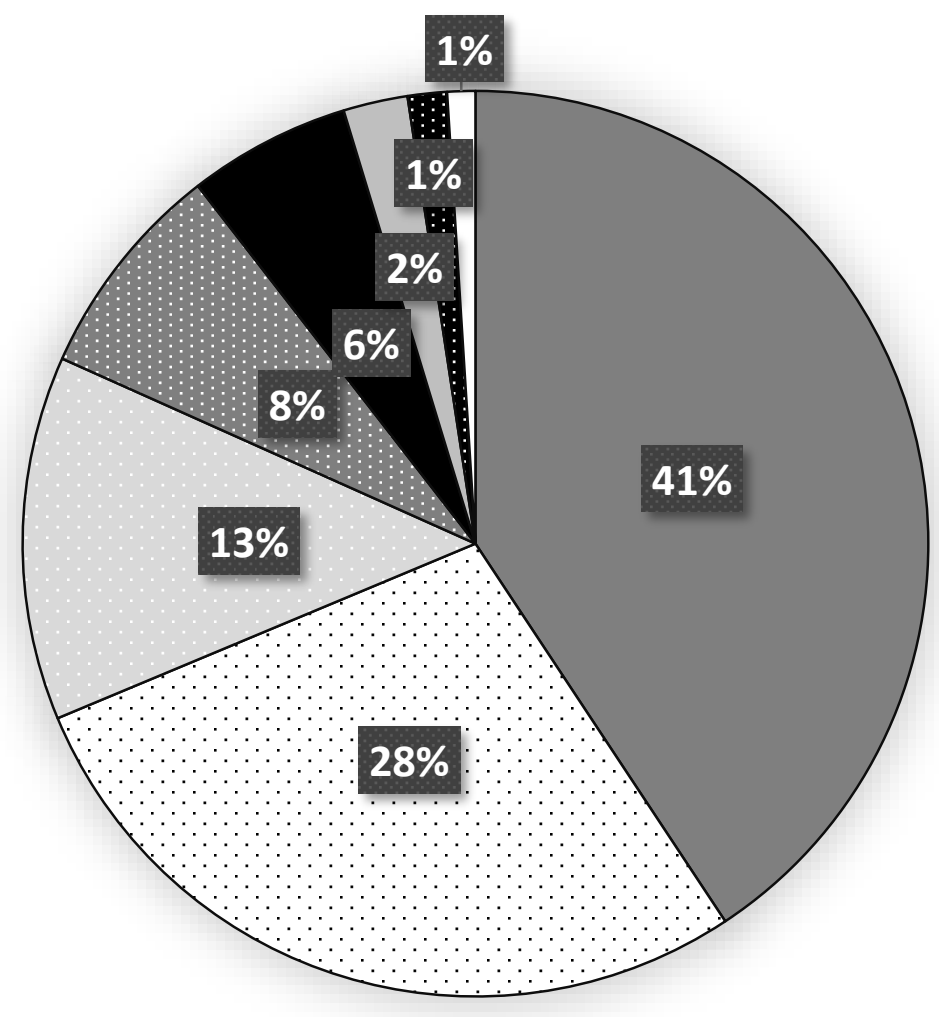

$\square$ Male earner/female domestic work

$\square$ Non-employed/low care

Dual-earners/dualcarers

- Female earner/shared domestic work

$\square$ Male earner long hours/female part-time +domestic

Male domestic work

Maler earner/female domestic long hours 
Table 1: Likelihood of being in each of the eight couple division of work types amongst couples in the UK Household Longitudinal Study wave 2, mutually adjusted in multivariate multinomial regression models $(N=8,513)$.

\begin{tabular}{|c|c|c|c|c|c|c|c|c|c|c|c|c|c|c|c|c|}
\hline & \multirow{2}{*}{\multicolumn{2}{|c|}{$\begin{array}{c}\text { Dual- } \\
\text { earners/low } \\
\text { care (Ref) } \\
\text { ( } \mathrm{n}=3,467)\end{array}$}} & \multicolumn{2}{|c|}{$\begin{array}{c}\text { Male } \\
\text { earner/female } \\
\text { domestic }(n= \\
2,379)\end{array}$} & \multicolumn{2}{|c|}{$\begin{array}{c}\text { Non- } \\
\text { employed/low } \\
\text { care }(n=1,106)\end{array}$} & \multicolumn{2}{|c|}{$\begin{array}{l}\text { Dual earners, dual } \\
\text { caregivers } \\
(n=666)\end{array}$} & \multicolumn{2}{|c|}{$\begin{array}{c}\text { Female } \\
\text { earner/shared } \\
\text { domestic }(n=492)\end{array}$} & \multicolumn{2}{|c|}{$\begin{array}{l}\text { Male earner long } \\
\text { hours/female } \\
\text { earner }+ \text { domestic } \\
\quad(n=196)\end{array}$} & \multicolumn{2}{|c|}{$\begin{array}{c}\text { Male long hours } \\
\text { domestic }(n=120)\end{array}$} & \multicolumn{2}{|c|}{$\begin{array}{l}\text { Male earner/female } \\
\text { long hours domestic } \\
\qquad(n=87)\end{array}$} \\
\hline & & & $\mathrm{OR}^{2}$ & SE & $\mathrm{OR}^{2}$ & SE & $\mathrm{OR}^{2}$ & SE & $\mathrm{OR}^{2}$ & SE & $\mathrm{OR}^{2}$ & $\mathrm{SE}$ & $\mathrm{OR}^{2}$ & SE & $\mathrm{OR}^{2}$ & SE \\
\hline Couple average age & & & $1.04^{* *}$ & $(0.006)$ & $1.11^{* *}$ & (0.009) & $1.05^{* *}$ & $(0.007)$ & $1.09 * *$ & (0.009) & 1.01 & $(0.01)$ & $1.10^{* *}$ & $(0.02)$ & $1.07 * *$ & $(0.02)$ \\
\hline Household income $^{1}$ & - & - & $0.44 * *$ & $(0.14)$ & $0.18^{* *}$ & $(0.021)$ & 0.98 & $(0.05)$ & $0.33 * *$ & $(0.25)$ & 1.03 & $(0.1)$ & $0.15^{* *}$ & $(0.52)$ & 0.52 & $(0.52)$ \\
\hline \multicolumn{17}{|l|}{ Number of children } \\
\hline $0-4$ years & - & - & $3.65^{* *}$ & $(0.1)$ & $3.05^{* *}$ & $(0.15)$ & 0.62 & $(0.28)$ & 1.26 & $(0.24)$ & 1.43 & $(0.24)$ & $4.41 * *$ & $(0.32)$ & $5.10 * *$ & $(0.25)$ \\
\hline $5-15$ years & - & - & $1.78 * *$ & $(0.06)$ & $1.27^{* *}$ & (0.09) & 0.95 & $(0.09)$ & 0.81 & (0.11) & 1.25 & $(0.13)$ & $2.43 * *$ & $(0.16)$ & $2.77^{* *}$ & $(0.12)$ \\
\hline \multicolumn{17}{|l|}{ Gender attitudes } \\
\hline Both egalitarian & - & - & REF & & REF & & REF & & REF & & REF & & REF & & REF & \\
\hline Both middling & - & - & $3.78^{* *}$ & $(0.19)$ & $1.51^{*}$ & $(0.2)$ & 1.12 & $(0.2)$ & $0.60 *$ & $(0.25)$ & 1.73 & $(0.41)$ & 1.76 & $(0.43)$ & $12.07^{*}$ & (0.98) \\
\hline Both traditional & & & $11.42 * *$ & $(0.18)$ & $3.85 * *$ & $(0.21)$ & 1.02 & $(0.25)$ & 0.81 & $(0.28)$ & $3.47 * *$ & $(0.43)$ & 2.34 & $(0.45)$ & $36.02 * *$ & $(0.94)$ \\
\hline Man more egalitarian & & & $3.77^{* *}$ & $(0.17)$ & $2.27 * *$ & (0.19) & 1.07 & $(0.18)$ & 1.01 & $(0.2)$ & $2.38^{*}$ & $(0.36)$ & 2.03 & $(0.38)$ & $9.21 *$ & (0.99) \\
\hline Woman more egalitaria & & & $2.75^{* *}$ & $(0.16)$ & $1.79 * *$ & $(0.17)$ & 0.82 & $(0.17)$ & 1.01 & $(0.16)$ & $2.25^{*}$ & $(0.32)$ & 0.88 & (0.39) & $11.10^{*}$ & $(0.94)$ \\
\hline \multicolumn{17}{|c|}{ Couple difference in qualifications } \\
\hline Equal & - & - & REF & & REF & & REF & & REF & & REF & & REF & & REF & \\
\hline Male higher & - & - & $1.43^{* *}$ & $(0.12)$ & 1.01 & $(0.13)$ & 0.96 & $(0.16)$ & $0.57 * *$ & $(0.18)$ & 0.81 & $(0.3)$ & 1.22 & $(0.32)$ & 1.51 & $(0.41)$ \\
\hline Female higher & - & - & $0.77 *$ & $(0.11)$ & $0.67 * *$ & (0.13) & 1.22 & $(0.14)$ & 0.98 & $(0.15)$ & 1.18 & $(0.28)$ & 1.10 & $(0.3)$ & 0.95 & $(0.38)$ \\
\hline
\end{tabular}

* $p<0.01, * p<0.05$

All analyses are weighted. Fit statistics for the model: Loglikelihood Ratio Test $=-202218$, AIC $=404686$, BIC $=405612$, Sample-Size Adjusted BIC $=405215$

1. Equivalised household income, $£ 1000$

2. Estimates shown are Odds Ratios. 